\title{
COMMENTARY
}

\section{Patients with diabetes in the intensive care unit; not served by treatment, yet protected?}

\author{
Sarah E Siegelaar*, J Hans Devries and Joost B Hoekstra \\ See related research by Vincent et al., http://ccforum.com/content/14/1/R12
}

\begin{abstract}
Diabetes is associated with severe complications and decreased life expectancy. However, in the previous issue of Critical Care, Vincent and colleagues report no difference in mortality between patients with insulintreated diabetes and patients without diabetes in the intensive care unit (ICU), despite larger severity of illness in the diabetes group at admission. This study contributes to the growing evidence that diabetes in itself is not a risk factor for ICU mortality, although the mechanisms are not yet fully understood. On the other hand, patients with diabetes seem not to benefit from tight glycemic control during their ICU stay. Different treatment approaches may be needed for patients with diabetes and patients with stress hyperglycemia.
\end{abstract}

As reported in the previous issue of Critical Care, Vincent and colleagues [1] investigated the possible increased risk of patients with insulin-treated diabetes for morbidity and mortality in the intensive care unit (ICU). Literature is conflicting at this point, with studies showing increased risk [2,3], decreased risk [4], or neutral risk [5,6]. In their analyses, Vincent and colleagues included 3,147 patients originally recruited for the Sepsis Occurrence in Acutely ill Patients (SOAP) study [7], including 226 (7.2\%) patients with a prior diagnosis of insulin-treated diabetes. No significant differences in ICU or 28-day hospital mortality were observed between the groups, even though patients with insulin-treated diabetes were sicker at baseline, as reflected by higher Simplified Acute Physiology Score (SAPS II) and Sequential Organ Failure Assessment (SOFA) score. From a Cox proportional hazards analysis correcting for differences in patient characteristics, it

*Correspondence: s.e.siegelaar@amc.uva.nl

Academic Medical Centre, Department of Internal Medicine, Meibergdreef 9, F4255, 1105 AZ Amsterdam, The Netherlands appeared that patients with insulin-treated diabetes were more likely to develop renal failure, but diabetes was not an independent predictor of ICU or 28-day mortality (hazard ratio 0.78 , confidence interval 0.58 to 1.07 , $P=0.12$ ). Patients were followed until death or hospital discharge or for 60 days. The latter mortality rates were not discussed, probably due to low numbers in the diabetes group at 60 days.

The diabetes population in the study of Vincent and colleagues consisted only of patients with a history of insulin-treated diabetes. This definition does not classify between type 1 and type 2 diabetes, and from the large type 2 diabetes population, only the insulin-treated proportion, around $25 \%$ of all type 2 diabetes patients, is captured. How this affects the conclusions is unknown. Also, the authors did not have the opportunity to collect data with respect to glucose regulation or insulin therapy, and this might have contributed to observed group differences.

Vincent and colleagues do not stand alone in their conclusions. Very recent descriptions of two large mixed ICU populations [4] and, more specifically, sepsis patients [6] also found no differences in mortality, and perhaps even less mortality, in diabetes compared with nondiabetes patients, despite larger morbidity in the former group. Larger morbidity and development of complications in diabetes can be explained by the often pre-existing organ dysfunction and pathophysiological alterations in the disease. This raises the intriguing question of how patients with diabetes manage to survive in the ICU despite an increased risk for a variety of complications such as bloodstream infections $[6,8]$ and renal failure [1], which are, at least in the non-diabetic population, independently associated with mortality $[9,10]$. Remarkably, there seems to be a lower incidence of acute lung injury in patients with diabetes [11].

There may be two sides to the diabetes coin. There is evidence that hyperglycemia caused by critical illness is not associated with mortality in patients with diabetes $[6,12,13]$, but on the other hand, patients with diabetes do not seem to benefit from intensive insulin therapy 
during their ICU stay [14]. This suggests that acute hyperglycemia in critical illness and hyperglycemia due to chronic diabetes are two distinct pathophysiological entities. Perhaps this is a call for an active search for preexisting diabetes since this is often undiagnosed at the time of an event leading to hospital admission.

Various mechanisms are proposed to explain the similar outcomes of patients with diabetes and those without it. Insulin may protect through anti-inflammatory effects [15] given that in the intensive insulin therapy era, many patients without diabetes are receiving insulin. Also, a higher body mass index may have a protective effect against ICU mortality and may also protect people with type 2 diabetes [16]. Adaptation to hyperglycemia might be a key mechanism. Oxidative stress, arising from inflammation and hyperglycemia, is known to cause endothelial damage through several mechanisms and is associated with poor outcome in the critically ill [17]. It is possible that because diabetes patients are already adapted to oxidative stress due to previous chronic exposure to hyperglycemia, the critical illness-induced oxidative stress is more harmful to non-diabetic patients because they have not yet activated cellular adaptation mechanisms.

Whatever the mechanism is, this elegant study by Vincent and colleagues contributes to the evidence that diabetes itself is not a risk factor for mortality in the ICU. Moreover, the likely higher complication and morbidity rates of patients with diabetes and different responses to hyperglycemia suggest the need for the implementation of different treatment algorithms for both groups.

\section{Abbreviation}

$\mathrm{ICU}$, intensive care unit.

\section{Competing interests}

The authors declare that they have no competing interests.

Published: 1 March 2010

\section{References}

1. Vincent J, Preiser J, Sprung C, Moreno R, Sakr Y: Insulin-treated diabetes is not associated with increased mortality in critically ill patients. Crit Care 2010, 14:R12.

2. Brown JR, Edwards FH, O'Connor GT, Ross CS, Furnary AP: The diabetic disadvantage: historical outcomes measures in diabetic patients undergoing cardiac surgery -- the pre-intravenous insulin era. Semin Thorac Cardiovasc Surg 2006, 18:281-288.
3. Slynkova K, Mannino DM, Martin GS, Morehead RS, Doherty DE: The role of body mass index and diabetes in the development of acute organ failure and subsequent mortality in an observational cohort. Crit Care 2006, 10:R137.

4. Graham BB, Keniston A, Gajic O, Trillo Alvarez CA, Medvedev S, Douglas IS: Diabetes mellitus does not adversely affect outcomes from a critical illness. Crit Care Med 2010, 38:16-24.

5. Pittet D, Thievent B, Wenzel RP, Li N, Gurman G, Suter PM: Importance of pre-existing co-morbidities for prognosis of septicemia in critically ill patients. Intensive Care Med 1993, 19:265-272.

6. Stegenga ME, Vincent JL, Vail GM, Xie J, Haney DJ, Williams MD, Bernard GR, van der Poll T: Diabetes does not alter mortality or hemostatic and inflammatory responses in patients with severe sepsis. Crit Care Med 2010, 38:539-545.

7. Vincent JL, Sakr Y, Sprung CL, Ranieri VM, Reinhart K, Gerlach H, Moreno R, Carlet J, Le G Jr, Payen D: Sepsis in European intensive care units: results of the SOAP study. Crit Care Med 2006, 34:344-353.

8. Michalia M, Kompoti M, Koutsikou A, Paridou A, Giannopoulou P, TrikkaGraphakos E, Clouva-Molyvdas P: Diabetes mellitus is an independent risk factor for ICU-acquired bloodstream infections. Intensive Care Med 2009, 35:448-454.

9. Vincent JL, Rello J, Marshall J, Silva E, Anzueto A, Martin CD, Moreno R, Lipman J, Gomersall C, Sakr Y, Reinhart K; EPIC II Group of Investigators: International study of the prevalence and outcomes of infection in intensive care units. JAMA 2009, 302:2323-2329.

10. Uchino S, Kellum JA, Bellomo R, Doig GS, Morimatsu H, Morgera S, Schetz M, Tan I, Bouman C, Macedo E, Gibney N, Tolwani A, Ronco C; Beginning and Ending Supportive Therapy for the Kidney (BEST Kidney) Investigators: Acute renal failure in critically ill patients: a multinational, multicenter study. JAMA 2005, 294:813-818.

11. Moss M, Guidot DM, Steinberg KP, Duhon GF, Treece P, Wolken R, Hudson LD, Parsons PE: Diabetic patients have a decreased incidence of acute respiratory distress syndrome. Crit Care Med 2000, 28:2187-2192.

12. Egi M, Bellomo R, Stachowski E, French CJ, Hart GK, Hegarty C, Bailey M: Blood glucose concentration and outcome of critical illness: the impact of diabetes. Crit Care Med 2008, 36:2249-2255.

13. Whitcomb BW, Pradhan EK, Pittas AG, Roghmann MC, Perencevich EN: Impact of admission hyperglycemia on hospital mortality in various intensive care unit populations. Crit Care Med 2005, 33:2772-2777.

14. Van den Berghe G, Wilmer A, Milants I, Wouters PJ, Bouckaert B, Bruyninckx F, Bouillon R, Schetz M: Intensive insulin therapy in mixed medical/surgical intensive care units. Diabetes 2006, 55:3151-3159.

15. Garg R, Chaudhuri A, Munschauer F, Dandona P: Hyperglycemia, insulin, and acute ischemic stroke: a mechanistic justification for a trial of insulin infusion therapy. Stroke 2006, 37:267-273.

16. Peake SL, Moran JL, Ghelani DR, Lloyd AJ, Walker MJ: The effect of obesity on 12-month survival following admission to intensive care: a prospective study. Crit Care Med 2006, 34:2929-2939.

17. Motoyama T, Okamoto K, Kukita I, Hamaguchi M, Kinoshita Y, Ogawa H: Possible role of increased oxidant stress in multiple organ failure after systemic inflammatory response syndrome. Crit Care Med 2003, 31:1048-1052.

doi:10.1186/cc8881

Cite this article as: Siegelaar SE, et al.: Patients with diabetes in the intensive care unit; not served by treatment, yet protected? Critical Care 2010, 14:126. 